\title{
Critical stresses arising in the destruction of a floating reinforced concrete pontoon
}

\author{
Dina Morozova ${ }^{1^{*}}$, Dmitrii Malakhov $^{2}$ \\ ${ }^{1}$ Moscow Polytechnic University, Moscow, Moscow, Russian Federation \\ ${ }^{2}$ The Moscow Automobile and Road State Technical University (MADI), Moscow, Russian \\ Federation
}

\begin{abstract}
The article discusses the stress-strain state of a reinforced concrete floating pontoon caused by critical stresses before its destruction. The investigation was motivated by the destruction of the pontoon, which occurred under extreme wind and wave impacts. A method for determining wind, wave and current loads is presented. The investigation was carried out on finite element computer models. As a result of the investigation, critical efforts and stresses were obtained, causing the destruction of the pontoon. The main conclusion of the conducted investigation is the possibility of using a floating reinforced concrete pontoon in waters with limited values of wind, wave effects and loads from the current.
\end{abstract}

\section{Introduction}

The article discusses the stress-strain state of a floating reinforced concrete pontoon, which arose as a result of a storm of $2 \%$ coverage (occurs once every 50 years) at a wind speed in the bay of $46 \mathrm{~m} / \mathrm{s}$ and a wave height of $2.5 \mathrm{~m}$. It is actual to determine the limiting values of wind and wave loads that cause critical stresses in a reinforced concrete pontoon, which must be considered when choosing the type of pontoon to prevent its destruction.

A review of scientific and technical literature showed the absence of a solution to this specific problem in the literary sources. When determining the wave, wind and flow loads acting on the pontoon, we used the dependencies developed based on many years of field investigations (Shaitan VS, VV Shuleikin, VF Gushchin), used in modern regulatory documents of the Russian Federation on hydraulic engineering, as well as conclusions and recommendations of modern investigators (Pilyaeva SI., Kantarzhi IG., Mordvintseva KP. and others).

The purpose of this investigation is to determine the critical forces and stresses destroying a reinforced concrete floating pontoon. The objectives of the investigation are to identify the optimal values of wind, wave and flow loads, at which it is possible to use the considered constructive solution of a reinforced concrete pontoon.

\footnotetext{
* Corresponding author: morozovadv@mail.ru
} 


\section{Methods}

The method for studying the stress-strain state of a reinforced concrete floating pontoon was based on the method for determining wind, wave and current loads set forth in the current regulatory document Code of Rules 38.13330. 2018. Loads and impacts on hydraulic structures (wave, ice and from ships).

The calculation recommendations contained in this Code of Rules were obtained based on numerous field investigations of previous years [1,2,3] and modern field investigations, laboratory [4] and numerical investigations [5], which make it possible to clarify existing and develop new calculation methods, as well as specify the loads acting on hydraulic structures, including the wave loading of piers $[6,7,8,9]$.

It should be noted that the reliability of the design of hydraulic engineering facilities, including piers made of reinforced concrete pontoons, is associated with taking into account all the loads and impacts on them $[10,11]$.

When performing the calculation, the article considers the extreme loading of the pontoon $[12,13]$. Loads on a reinforced concrete pontoon (Fig. 1a) were calculated for real conditions at a wind speed of $46 \mathrm{~m} / \mathrm{s}$, and a wave height of $2.5 \mathrm{~m}$, at which the pontoons collapsed with pollution of the bay by crumbling parts of polystyrene foam blocks (Fig. 1b) placed in the body of the ribbed reinforced concrete slab of the pontoon and ensuring its flotation.

In [14], the definition of operational loads for reinforced concrete pontoon of river piers is given. The conditional load on the pontoon associated with the stay of people on it, cargo moved to the pontoon, etc., is considered. It is assumed that the ship at the pier will interact with the pontoon [15]. Different intensities of wind and wave loading can be expected for pontoons of the river and sea piers [16].

As you know, even load-bearing reinforced concrete structures of heated buildings can collapse from moisture and temperature changes as a result of prolonged construction of a building or a break in its construction [17]. In this case, the following defects of reinforced concrete structures may occur, leading to a decrease in the design bearing capacity. Cracks and delamination of concrete appear due to repeated alternating exposure to negative and positive temperatures, corrosion of steel embedded parts and reinforcement outlets, corrosion of frameworks and reinforcement meshes due to water seepage into the thickness of structures. Corrosion of concrete also takes place, that is, the process of destruction of its structure due to the dissolution and washout of the constituent parts of the cement stone by water, the formation and crystallization of hardly soluble substances in the pores of the concrete, the destruction of cement stone by substances contained in water and air; damage to concrete by fungi, mosses, plants. Reinforced concrete pontoons, during their operation, constantly interact with the aquatic environment; therefore, the described damage manifests in them to a greater extent.

\section{Results and Discussion}

In [14], the structural solution of a reinforced concrete pontoon is described in detail. The stress-strain state of the pontoon will depend on its constructive solution, including the features of its fastening [18]. 

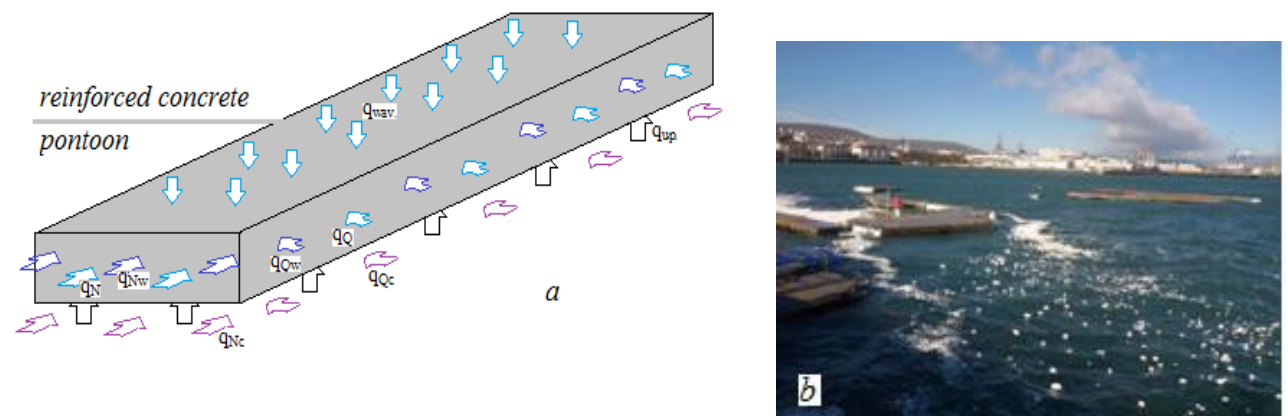

Fig. 1. The scheme of loading a reinforced concrete pontoon (a), a view of the destroyed floating reinforced concrete pontoons and clogging of the sea bay (b)

The design solution of a floating reinforced concrete pontoon is shown in Fig. 2. Slab dimensions: length is $\mathrm{L}=14.88 \mathrm{~m}$; the width of the slab is $\mathrm{B}=2.4 \mathrm{~m}$. The flotation of the pontoon slabs is achieved by filling the space between the edges of the slab with a polymer material - expanded polystyrene, with a density $\rho_{\text {II }}=0.3 \mathrm{kN} / \mathrm{m}^{3}$.

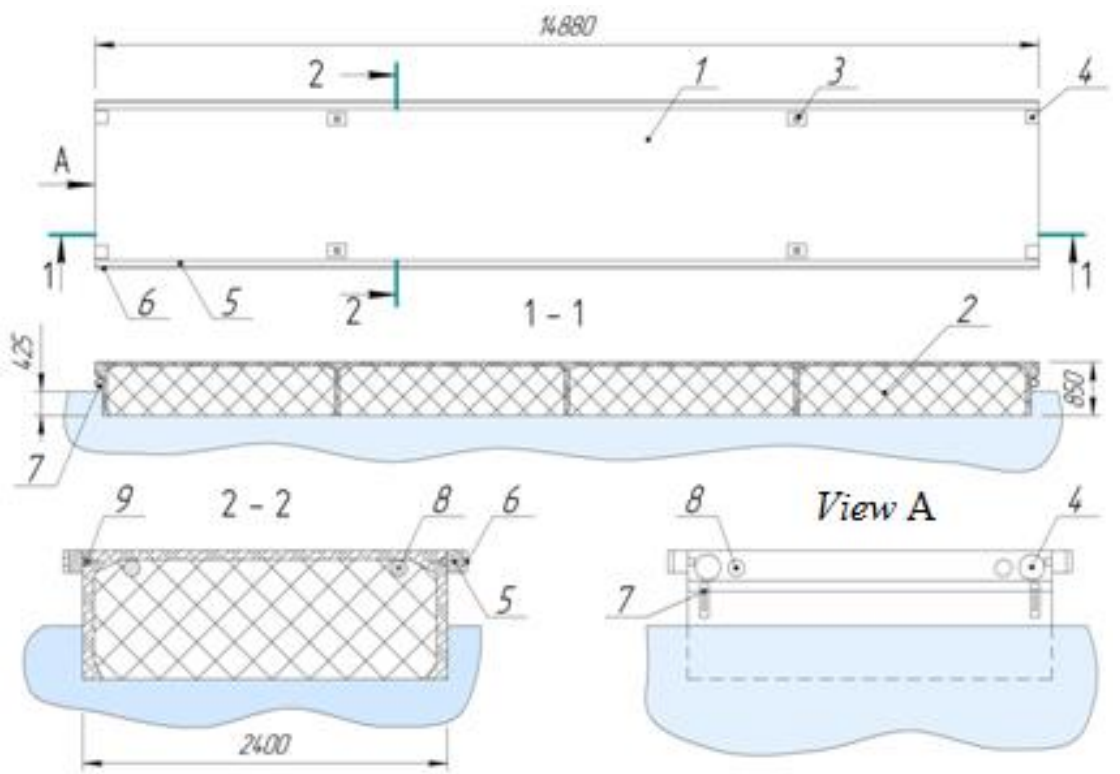

Fig. 2. Constructive solution of a floating reinforced concrete pontoon: 1 is reinforced concrete pontoon frame, 2 are four polystyrene foam blocks, 3 is mooring bollard, 4 is steel adapter, 5 is fender, 6 is outer board, 7 is anchor loop, 8 is cable channel, 9 is fastening guide

The case under consideration refers to storms of $2 \%$ probability with a wind speed in the bay of $46 \mathrm{~m} / \mathrm{s}$. When determining the external loads acting on a floating pontoon, the methodology outlined in Code of Rules 38.13330.2018 was used, developed based on the results of many years of field research carried out by hydraulic scientists, and summarized in the Code of Rules. The formulas given below for determining the longitudinal and transverse forces from the effects of wind, waves and from the current, as well as the formulas for auxiliary empirical coefficients, are indicated in Code of Rules 38.13330. 2018. Loads and impacts on hydraulic structures (wave, ice and from ships. The article 
provides links to the dependencies, graphs and tables required for the calculation, taken from this Code of Rules.

The calculated values of the transverse $Q_{w}$ and longitudinal $N_{w}$ components of the wind force on floating objects are determined by the formulas (Section 6.2):

$$
\begin{gathered}
Q_{w}=73.6^{*} 10^{-5 *} * \gamma_{f} A_{q} V_{q}^{2} \xi=73.6 * 10^{-5} * 1.4 * 6.35^{*} 46^{2} * 1=13.8 \mathrm{kN} \\
N_{w}=49.0 \cdot 10^{-5 *} \gamma_{f} A_{n} V_{n}^{2} \xi=49.0 * 10^{-5} * 1.4 * 1.02 * 46^{2 *} 1=1.5 \mathrm{kN}
\end{gathered}
$$

where $A_{q}=6.35 \mathrm{~m}^{2}$ is lateral surface area of the sail (silhouettes) of a floating reinforced concrete pontoon, $\mathrm{m}^{2}$;

$A n=1.02 \mathrm{~m}^{2}$ is frontal surface area of the sail (silhouettes) of a floating reinforced concrete pontoon, $\mathrm{m}^{2}$;

$V_{q}$ and $V n$ are, respectively, the transverse and longitudinal components of the anemometric wind speed, $\mathrm{m} / \mathrm{s}$, taken following a real event;

$\xi$ is a coefficient depending on the largest horizontal dimension $\alpha_{h}, \mathrm{~m}$, transverse or longitudinal silhouettes of the surface part of a floating object, taken according to Table 8 .

When the object is parked for a long time (groups 3 and 4 of Table 7), the coefficient $\xi$ $=1 ; \gamma_{f}=1.4$ is the coefficient of reliability for wind load, adopted following Code of Rules 20.13330. 2016. Loads and Impacts.

Sail areas are determined taking into account the areas of shielding barriers located on the windward side (Appendix I).

Loads from the impact of wind on a running meter of the slab: transverse $-q_{Q w}=$ $13.8 / 14.88=0.93 \mathrm{kN} / \mathrm{m}$; longitudinal $-q_{N w}=1.5 / 2.4=0.63 \mathrm{kN} / \mathrm{m}$.

The calculated values of the transverse $Q c$ and longitudinal $N c$ components of the force from the action of the flow on floating objects are determined by the formulas (35), (36):

$$
Q_{c}=C_{y} \frac{\rho}{2} A_{l} V_{t}^{2}, N_{c}=C_{x} \frac{\rho}{2} A_{t} V_{l}^{2}
$$

where $C y, C x$ are the generalizing coefficients of the longitudinal and transverse forces of the current, determined taking into account the ratio of the draft of the floating object and the depth of the water (Appendix K).

We calculate $C y$ by the formula (K.4): $C y=C y^{\infty}+\left(\mathrm{C}_{\mathrm{y}}{ }^{1}-C_{y}{ }^{\infty}\right) *\left(\mathrm{~T}_{\mathrm{k}} / \mathrm{d}\right){ }^{\mathrm{k} 1}$,

We accept the minimum values:

$\mathrm{d}=5.5 \mathrm{~m}$ is average water depth in the bay at the location of the pontoon;

$C_{y}{ }^{\infty}=0.4 ; \mathrm{C}_{\mathrm{y}}{ }^{1}=2$ (according to table K.2);

$\mathrm{k}_{1}=2$ (Appendix K);

$\rho=10.3 \mathrm{kN} / \mathrm{m}^{3}$ is the average density of seawater; $\mathrm{m}^{2}$

$A_{l}$ and At is respectively, lateral and frontal underwater sail area of floating objects,

$V t$ and $V_{l}$ are the transverse and longitudinal components of the current velocity, taken from meteorological measurements during storms of $2 \%$ probability, equal to $1.2 \mathrm{~m} / \mathrm{s}$;

$T_{k}$ is the amount of draft of a floating object.

We take $T_{k}=0.425 \mathrm{~m}$, equal to half the height of the edges of the slab.

$$
\begin{gathered}
C y=0.4+(2-0.4) *(0.425 / 5.5) * 2=0.4 \\
Q c=0.4 * 10.3 * 6.35 * 1.22 / 2=18.8 \mathrm{kN}
\end{gathered}
$$


Transverse load from the effect of flow on a running meter of the slab: $q_{Q c}=18.8 / 14.88$ $=1.3 \mathrm{kN} / \mathrm{m}$. The coefficient of resistance of the longitudinal load from the flow $C x$, defined as the sum of the coefficient of resistance of the shape of a floating object, the coefficient of resistance due to the friction of water on the wetted surface of the object, and the coefficient of resistance of the object, is calculated by the formula (K.1):

$C_{x}=0.1 *\left[1.0+C_{t} * L_{s} *\left(1.7 / B_{k}+35 * \delta / T_{k}\right)\right]+1.2 * L_{s} / T_{k} * A_{R}$,

where $C t$ is the coefficient of frictional resistance calculated by the formula (K.2) (Appendix K):

$C_{t}=0.075 /\left(\log \mathrm{R}_{\mathrm{en}}-2\right)^{*^{2}}$

$R_{e n}$ is Reynolds number, determined by the formula (K.3).

$R_{e n}=\mathrm{Vt} * \mathrm{Ls} / \mathrm{v}=1.2 * 14.88 / 1.0 * 10^{-6}=17856 * 10^{3}$;

$C_{t}=0.075 /\left(\log 17856 * 10^{3}-2\right)^{* 2}=0.075 /(7.25-2)^{2}=0.003$;

$L s$ is the length of the floating object (plate) along the waterline, equal to $14.88 \mathrm{~m}$;

$v$ is the kinematic coefficient of viscosity of sea water, taken equal to $1.0^{*} 10^{-6}, \mathrm{~m}^{2} / \mathrm{s}$;

$\delta$ is the coefficient of the overall completeness of the object;

$B_{k}$ is the width of the floating object at the considered load, equal to $2.4 \mathrm{~m}$;

$A_{R}$ is a value characterizing the area of a floating object, taken according to the data in Table K.1, depending on its type.

We accept $A_{R}=1 ; \delta=1 . C_{x}=0.1 *[1.0+0.003 * 14.88 *(1.7 / 2.2+35 * 1 / 0.425)]$ $+1.2 * 14.88 / 0.425 * 1=42.5$.

Longitudinal $N c$ component of the force from the action of the current on the floating object:

$$
N c=C_{x} \rho A_{t} V_{l}^{2} / 2=42.510 .3 * 1.02 * 1.2^{2} / 2=321.5 \mathrm{kN}
$$

Longitudinal load from the effect of flow on a running meter of the slab: $q N c=$ $321.5 / 2.4=134.0 \mathrm{kN} / \mathrm{m}$.

The calculated maximum values of the transverse $Q$ and longitudinal $N$ horizontal forces from the action of waves on floating objects are determined by the formulas (37), (38):

$$
\begin{gathered}
Q=\mathfrak{x}^{*} \gamma_{1 * \rho^{*}} \mathrm{~g}^{*} h^{*} A_{l}, \\
N=\mathfrak{x}^{*} \rho^{*} g^{*} h^{*} A_{t}, \text { where }
\end{gathered}
$$

$\mathfrak{X}$ is coefficient depending on the draft ds, m, of the floating object; it is accepted according to the schedule (Figure 15);

$\rho_{b}=1.03 \mathrm{t} / \mathrm{m}^{3}=10.3 \mathrm{kN} / \mathrm{m}^{3}$ is average density of seawater;

$\gamma_{1}$ is the coefficient taken according to Table 9, in which: al is the largest horizontal size of the longitudinal silhouette of the underwater part of the floating object, $\mathrm{m}$;

$g=9.8 \mathrm{~m} / \mathrm{s}^{2}$ - acceleration of gravity;

$h$ is the wave height according to meteorological observations, equal to $2.5 \mathrm{~m}$;

$A_{l}$ and $A_{t}$ are designations that are the same as in formula 6.3.

$$
\begin{gathered}
Q=0.85 * 1 * 1.03 * 9,8 * 2.5 * 6.35=136.2 \mathrm{kN} \\
N=0.85 * 1.03 * 9.8 * 2.5 * 1.02=21.9 \mathrm{kN}
\end{gathered}
$$

Loads from the impact of waves on a running meter of a slab: transverse is $q_{Q}=$ $136.2 / 14.88=9.16 \mathrm{kN} / \mathrm{m}$, longitudinal is $q_{N}=21.92 .4=9.13 \mathrm{kN} / \mathrm{m}$.

As a first approximation, for a preliminary assessment of the stress state of the reinforced concrete slab of the pontoon, we take the vertical wave pressure on the slab as a uniformly distributed load with an ordinate: 
$q_{\text {wave }}=\rho_{6} * h_{B} * B=10,3 * 2,5 * 2,4=61.8 \mathrm{kN} / \mathrm{m}$, where:

$h_{B}=2.5 \mathrm{~m}$ - wave height; $B=2.4 \mathrm{~m}$ - slab width.

The weighing pressure acting on the plate:

$q_{u p}=-\rho_{b} * h_{p} * B=-10.3 * 0.85 * 2.4=-21.0 \mathrm{kN} / \mathrm{m}$, where:

$h_{p}=0.85 \mathrm{~m}$ is the height of the edges of the slab;

$B=2.4 \mathrm{~m}$ is slab width.

Figure 3 shows the geometry of the longitudinal and cross-section of the pontoon slab, indicating the areas where the calculated loads are applied.

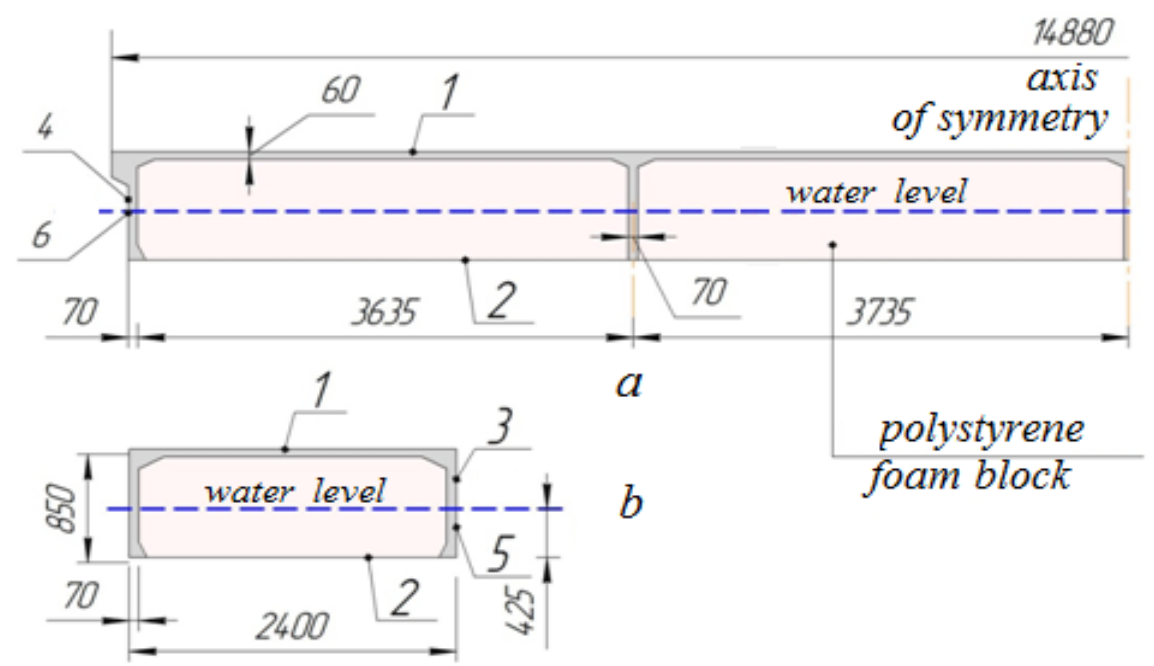

Fig. 3. The geometry of the longitudinal (a) and transverse (b) sections of the pontoon with the indication of the surfaces of application of the calculated loads: 1 is the surface of the action of wave pressure on the horizontal surface of $\mathrm{q}_{\text {waves }} ; 2$ is surface of action of weighing pressure $\mathrm{q}_{\mathrm{sv}} . ; 3,5$ is surface of transverse pressure from the action of $q_{Q}$ waves; 3 is surface of transverse pressure action from wind $q_{Q w} ; 4,6$ is surface of action of longitudinal pressure from the action of waves $q_{N} ; 3$ is surface of action of longitudinal pressure from wind $q_{N w} ; 5$ is surface of action of transverse pressure from the action of flow $q_{Q c}, 6$ is surface of action of longitudinal pressure from action of flow $q_{N_{c}}$

The loads from the tension of the ropes are taken according to the methodology set forth in Code of Rules 38.13330.2018 (clauses 6.2; 6.3) to determine the forces in the mooring lines in ships, taking into account the transverse component of the total force $Q_{t o t}, \mathrm{kN}$, from the total effect of the wind on one design vessel and currents.

Values $Q_{\text {tot }}=Q_{w}+Q_{c}=13.8+18.8=32.6 \mathrm{kN}$.

The force $S$ perceived by one node at the level of the upper plane of the slab (Figure 17) is determined by the formula:

$$
S=\frac{Q_{\text {tot }}}{n \cdot \sin \alpha \cdot \cos \beta}=32.6 / 4 * \sin 30^{\circ} * \cos 30^{\circ}=18.8 \mathrm{kN}, \text { where: }
$$

$n=4$ is the number of working pedestals (in our case, the nodes for attaching the cables to the plate), taken according to table 11 ;

$\alpha, \beta$ are tilt angles of the cable, degrees, taken according to table 12 .

Table 1 shows the calculated values of the loads applied to the surfaces indicated by positions 1 ... 6 in Figure 3 of the floating pontoon for two calculated cases: at a wind speed of $10 \mathrm{~m} / \mathrm{s}$ (1st case) and at a wind speed of $46 \mathrm{~m} / \mathrm{s}$ (2nd case). 
The floating reinforced concrete pontoon is reinforced with nets and individual rods. The meshes are installed in the top slab with a thickness of $60 \mathrm{~mm}$ and in the longitudinal and transverse walls with a thickness of $70 \mathrm{~mm}$. The meshes are made of reinforcing bars $\varnothing 8 \mathrm{~A} 500 \mathrm{C}$ and have a mesh size of $200 \times 200 \mathrm{~mm}$. Additional reinforcing bars $\varnothing 10 \mathrm{~A} 500 \mathrm{C}$, $\varnothing 12 \mathrm{~A} 500 \mathrm{C}, 16 \mathrm{~A} 500 \mathrm{C}, \varnothing 8 \mathrm{~A} 500 \mathrm{C}$ are installed in the ribs of the pontoons.

For the manufacture of the pontoon, concrete B45 was used. Depending on the concrete class, the thickness of the protective layer of reinforcement for structural elements of the pontoon can be taken as $45 \mathrm{~mm}, 40 \mathrm{~mm}$ or $25 \mathrm{~mm}$. Structurally, the pontoon is a ribbed reinforced concrete slab (рисунок 3 ).

Table 1. Calculated values of loads applied to the surfaces of the floating pontoon

\begin{tabular}{|c|c|c|c|c|}
\hline № & $\begin{array}{c}\text { Name and designation of } \\
\text { loads }\end{array}$ & $\begin{array}{c}\text { Surface } \\
\text { position }\end{array}$ & $\begin{array}{c}\text { Calculated values } \\
\text { of loads at a wind } \\
\text { speed of } 10 \mathrm{~m} / \mathrm{s}, \\
\mathrm{kN} / \mathrm{m}^{2}\left(1^{\text {st }} \text { case }\right)\end{array}$ & $\begin{array}{c}\text { Calculated values } \\
\text { of loads at a wind } \\
\text { speed of } 46 \mathrm{~m} / \mathrm{s}, \\
\mathrm{kN} / \mathrm{m}^{2}\left(2^{\text {nd }} \text { case }\right)\end{array}$ \\
\hline 1 & $\begin{array}{c}\text { Wave pressure on a } \\
\text { horizontal surface } \mathrm{q}_{\mathrm{wav}}\end{array}$ & 1 & $61.8 / 2.4=25.75$ & $61.8 / 2.4=25.75$ \\
\hline 2 & $\begin{array}{c}\text { Weighing pressure } \mathrm{q}_{\text {up }} \\
\text { the action of waves } q_{Q}\end{array}$ & 2 & $21 / 2.4=8.75$ & $-21 / 2.4=-8.75$ \\
\hline 3 & $\begin{array}{c}\text { Transverse pressure from } 5 \\
\text { the }\end{array}$ & $9.16 / 0.85=10.78$ & $9.16 / 0.85=10.78$ \\
\hline 4 & $\begin{array}{c}\text { Transverse pressure from } \\
\text { wind } q_{O w}\end{array}$ & 3 & $0.05 / 0.425=0.12$ & $0.93 / 0.425=2.19$ \\
\hline 5 & $\begin{array}{c}\text { Transverse pressure from } \\
\text { the action of the current } q_{O c}\end{array}$ & 5 & $0.18 / 0.425=0.42$ & $1.3 / 0.425=3.06$ \\
\hline 7 & $\begin{array}{c}\text { Longitudinal pressure from } \\
\text { waves } q_{N}\end{array}$ & 4 и 6 & $9.13 / 0.85=10.74$ & $9.13 / 0.85=10.74$ \\
\hline 8 & $\begin{array}{c}\text { Longitudinal wind pressure } \\
q_{N w}\end{array}$ & 4 & $0.04 / 0.425=0.09$ & $0.63 / 0.425=1.48$ \\
\hline & $\begin{array}{c}\text { Longitudinal pressure from } \\
\text { the action of the current } q_{N c} .\end{array}$ & 6 & $18.8 / 0.425=44.3$ & $134.0 / 0.425=$ \\
\end{tabular}

When carrying out a computer calculation [19, 20], a reinforced concrete pontoon was modeled using the LIRA-SAPR software package. The geometry of the design scheme included plate elements of the upper flange of the ribbed pontoon slab, its longitudinal and transverse ribs. Additional reinforcing bars of the pontoon slab ribs were modeled with bar elements, similar to the modeling of hidden frames.

The pontoon was fastened in the places of its anchoring in the lower corner zones of the pontoon slab. The strength and deformation characteristics of the materials of the reinforced concrete slab of the pontoon were set.

The loads were set following the loading table. The results of the static calculation are shown in Figure 4. The strength calculation showed the insufficient reinforcement of the pontoon slab to ensure its bearing capacity at a wind speed of $46 \mathrm{~m} / \mathrm{s}$. 


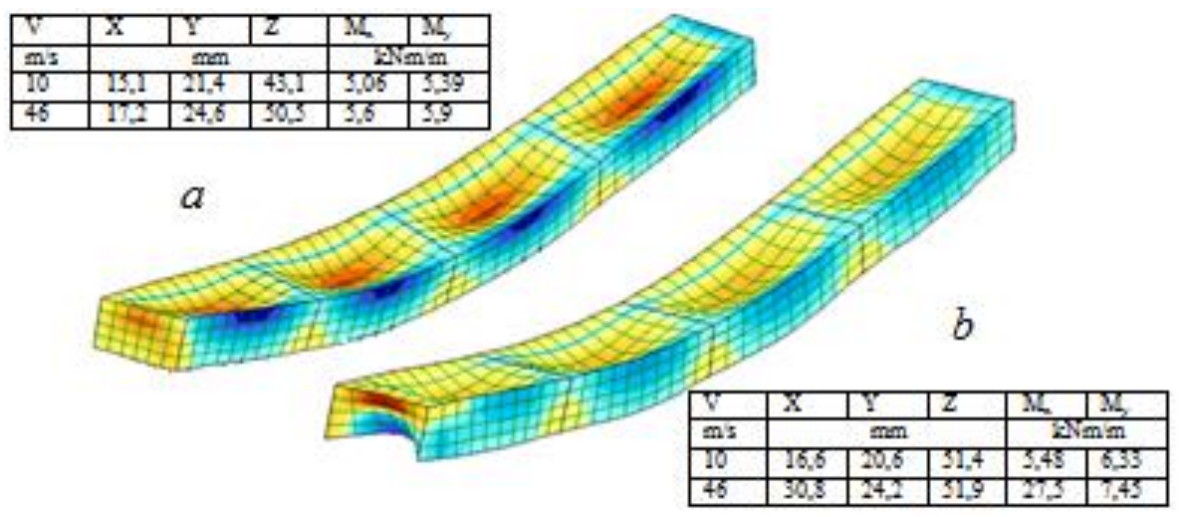

Fig. 4. Isofields of bending moments on a deformed scheme for a pontoon when it is loaded by the action of waves, wind and current in the longitudinal (a) and transverse directions (b)

\section{Conclusions}

1. As a result of calculating the stress-strain state of a reinforced concrete slab of a floating pontoon using a finite element model of the LIRA-SAPR software package under the influence of waves, wind and currents, maximum stresses and displacements were obtained in graphical and tabular form. The calculation results showed that the reinforcement of a given diameter installed in the slab does not provide the bearing capacity of the pontoon slab, which caused its destruction at a wind speed of $46 \mathrm{~m} / \mathrm{s}$.

2. Deformations of the outer transverse edges of the slab are significant and can lead to the separation of the expanded polystyrene blocks placed in the body of the ribbed reinforced concrete slab of the pontoon and providing its flotation.

3. Concrete protective layer equal to $25 \mathrm{~mm}$ does not meet the requirements of Code of Rules 41.13330.2012. Concrete and reinforced concrete structures of hydraulic structures, which can lead to accelerated corrosion of reinforcement.

4. The values of stresses and deformations of the elements of the reinforced concrete slab of the pontoon obtained as a result of the studies showed that at a wind speed of $46 \mathrm{~m} / \mathrm{s}$ and a wave height of $2.5 \mathrm{~m}$, they reached their limiting values, which led to the destruction of the pontoon. Therefore, in sea bays with possible extreme storms, piers of a different type should be used.

\section{References}

1 Shaitan VS., Shaitan KV., Morozova DV. Protection of earth slopes of hydraulic structures. Balkema A.A. / Rotterdam/ Brookfield/. p.488, (1997)

2 Shuleikin VV. State-of-the-art in the kinematics and dynamics of wind waves as the basis for developing methods of their analysis. Proc. Coord. Conf. Hydraulic Engineering, VNIIG, Energiya, Leningrad. vol. 50. (1969)

3 Gushchin VF. Probability of exceedance of design height of waves based on observations at the Rybinsk reservoir, In: Research Papers on Hydrology, Gidrometeoizdat, Leningrad. no. 6. (1966)

4 Pilyaev SI. Questions of the methodology of laboratory wave research on the territory of ports protected by protective structures. Hydraulic engineering. 11. pp.32$37,(2019)$ 
5 Kantarzhi IG., Mordvintsev KP. Numerical studies of the port water area security. Hydraulic engineering. 5. pp.45-52, (2019)

6 Zuev ND., Shulko AS. Study of the coefficient of reflection of waves from the overflow slope bank protection structure. Hydraulic engineering. 11. pp.41-44, (2018)

7 Levkevich VE. Dynamics of coastal processes of channel, filling and lacustrine reservoirs in Belarus. Minsk: Law and Economics. p.202, (2015)

8 Ostyakova AB. Interaction of waves with a coastal slope composed of non-cohesive soils. Hydraulic engineering. 5. pp.30-35, (2020)

9 Kivva SL., Shunko NV. Wave run-up on permeable fixed slopes. Engineering and construction journal. M. 6. pp.13-23, (2014)

10 Tamrazyan AG., Bulgakov SN., Rakhman IA., Stepanov AY. Reducing the risks in construction in emergency situations of natural and man-made nature. $\mathrm{M}$.: Publishing house ASV. p.304, (2012)

11 Tamrazyan AG. That evaluation of determining the risk level of extremal situations according to the main signs of its display on structure. Beton and Zhelezobeton. 5. pp.8-11, (2001)

12 Morozova DV., Malakhov DY. Analysis of the stress-strain state of floating reinforced concrete structures. Technology of the textile industry. 6 (378). pp.209-214, (2018)

13 Stepanov AP., Malakhov DY. Sea-going vehicle and sections of the surf zone. Automotive industry. 4. pp.20-22, (2002)

14 Borisov AM., Gingerbread KN. Design of the structure of the hull of reinforced concrete berthing pontoons. Bulletin VGAVT, 60.

15 Kantarzhi IG., Gogin AG. Modeling the impact of wind waves on a berth with a moored vessel. Hydraulic engineering. 1. pp.50-56, (2020)

16 Novoselov PN. The modern yacht port is the marina. Practice of creation. p.112, Moscow, (2011)

17 Malakhova AN., Balakshin AS. Damage to reinforced concrete load-bearing structures resulting from prolonged construction of buildings or an interruption in their construction. Textile industry technology. 2 (374). pp.214-219, (2018)

18 Levachev SN., Galimov IM., Filippov VV., Nemolochnov AG, Zubachev NA. Mooring structure with a rigid anchor device. Hydraulic engineering. 10. pp.31-36, (2018)

19 Gorodetsky AS., Laznyuk MV. Modern technologies of automated calculation and design of reinforced concrete structures. Building materials, equipment, technologies of the XXI century. 5. pp.62-63, (2007)

20 Gorodetsky AS., Evzerov ID. Computer models of structures. M., ASV. p.360 (2009) 